\title{
Plant-based meat and dairy substitutes on the Norwegian market: comparing macronutrient content in substitutes with equivalent meat and dairy products
}

\author{
Live Edvardsen Tonheim, Elisabeth Austad, Liv Elin Torheim and Sigrun Henjum* \\ Department of Nursing and Health Promotion, Faculty of Health Science, Oslo Metropolitan University, 0130 Oslo, Norway
}

(Received 10 June 2021 - Final revision received 29 December 2021 - Accepted 10 January 2022)

Journal of Nutritional Science (2022), vol. 11, e9, page 1 of 8

doi:10.1017/jns.2022.6

Abstract

Objective: To assess and compare the macronutrient and salt content in meat and dairy substitutes available on the Norwegian market. Design: Comparison between substitute products and two groups of meat and dairy products where one group represented the healthiest option (Keyhole) and one the most used option (Regular). Kruskal-Wallis test with pairwise comparison was conducted on categories with more than two groups, and Mann-Whitney $U$ test was conducted on categories with two groups. Setting: Online stores in Norway. Hundred and two meat substitute products and 173 milk and dairy substitute products on sale spring and autumn 2020 were assessed; additionally, ninety-eight equivalent meat products and 105 milk and dairy products. Results: While Keyhole and Regular meat did not contain fibre, meat substitutes contained 3.5-5.0 g fibre per $100 \mathrm{~g}$. The saturated fat content in meat substitutes was on average 1.9 times lower than in Keyhole products and 5.8 times lower than in Regular products. Milk and dairy substitutes contained 3.2 and 3.4 times less protein than Keyhole and Regular products, respectively. Conclusions. The study results indicate that meat and dairy substitutes on the Norwegian market vary in nutritional composition. Compared to Keyhole and Regular, substitutes contained lower levels of saturated fat, meat substitutes contained higher levels of fibre and milk and dairy substitutes less protein. Future studies should include content of micronutrients for a more comprehensive assessment.

Key words: Dairy substitutes: Macronutrients: Meat substitutes: Milk substitutes: Online stores: Salt content

\section{Introduction}

A shift towards more plant-based diets is named as one of the measures needed to combat both climate change and noncommunicable diseases $(\mathrm{NCDs})^{(1,2)}$. Livestock production alone is responsible for about $14 \%$ of global anthropogenic greenhouse gas emissions ${ }^{(3)}$. In addition, animal-source foods require more environmental resources in terms of fresh water and land use compared with plant-based foods ${ }^{(1,4)}$. Given the predicted population growth and increased affluence of low- and middle-income countries, the global demand for animal-source foods is expected to surpass the planet's capacity in $2050^{(5-7)}$.

Unhealthy or inadequate diets are the leading causes of death and loss of healthy life years worldwide ${ }^{(8)}$. According to the Global Burden of Disease study, 11 million deaths by NCDs are diet-related ${ }^{(8)}$. In Norway, an unhealthy diet is one of the three main risk factors for premature mortality ${ }^{(9)}$. Although healthy diets can be composed in many different ways, there is general agreement that the consumption of processed and red meats should be limited ${ }^{(10)}$, and the Norwegian dietary guidelines recommend a maximum of $500 \mathrm{~g}$ per week $^{(11)}$. There is equally strong evidence of the health benefits of wholegrain, fruits, non-starchy vegetables and pulses/ legumes. However, the place of dairy products in a healthy diet is debated ${ }^{(12)}$. In Norway, a daily intake of low-fat dairy is recommended, while a reduction in whole-fat dairy products is advised ${ }^{(11)}$. Further recommendations include choosing wholegrain, increasing the amounts of fruits, berries and vegetables, and limiting the intake of sugar, salt and saturated fat.

* Corresponding author: Sigrun Henjum, email shenjum@oslomet.no 
To help Scandinavian consumers make healthy food choices, the Keyhole front-of-pack label is used to identify options with a more beneficial nutrient profile (less saturated fat, salt and sugar, and more dietary fibre) in a given category ${ }^{(13)}$. The Keyhole is a voluntary endorsement scheme, similar to the 'Choices logo' used in Poland and the Czech Republic, and the 'Heart Symbol' used in Finland ${ }^{(13,14)}$. As a simple labelling scheme, it provides information about the total product, not nutrient content, as the more complex 'UK Multiple Traffic Lights' or the Australasian 'Health Star Rating,(14).

As in most Western countries, Norwegian meat consumption has steadily increased since the $1970 \mathrm{~s}^{(15)}$. Consumption of cheese and yoghurt also continues to rise, whereas demand for milk is decreasing. Nevertheless, in recent years, flexitarian eating (cutting down on meat and other animal-source foods on a regular basis) has become more common ${ }^{(16)}$. Simultaneously, consumer demand for plant-based products substituting meat and dairy, such as plant-based 'milk', burgers and sausages, has increased ${ }^{(17,18)}$. Consumer concerns about health and sustainability are suggested as one of the drivers for this increasing demand ${ }^{(19)}$. In a Norwegian study on meat-free habits, a clear majority $(71 \%$ ) named health as the main reason for wanting to reduce meat consumption ${ }^{(16)}$. Another motivation was concern for the environment. Plant-based eating is associated with being 'healthy' and 'sustainable'(20). This might contribute to plant-based substitutes being uncritically, and possibly wrongly, perceived as healthy and sustainable.

Plant-based meat substitutes have been available for many years, but mainly marketed to vegetarians and vegans ${ }^{(21)}$. The early meat substitutes were mostly made from soy protein and subjected to a low grade of processing, i.e. tofu and tempeh $^{(22)}$. Gradually, however, technological developments have resulted in products intended to mimic meat in taste and texture $^{(23)}$. This new generation of plant-based meat analogues (PBMA) is based not only on soy, but also on protein isolates from peas, wheat, chickpeas, beans and fungi ${ }^{(17,24)}$. The increasing selection of non-dairy milk substitute products seems to appeal to cow's milk consumers as well as to vegetarians and vegans or to people with intolerances or allergies ${ }^{(25)}$. In addition to plant-based milk, a wide range of other nondairy products is available, including plant-based alternatives for cheese, yoghurts, ice cream and cream $^{(12)}$.

Although plant-based substitutes may provide a higher intake of recommended food groups compared with their animal counterparts, the nutrient composition of these products can vary widely ${ }^{(24,26,27)}$. Meat substitutes are suggested to contain more fibre and less total and saturated fat compared with their meat counterparts ${ }^{(26)}$. Furthermore, these products have been found to contain comparable amounts of protein and iron $^{(22)}$, but higher amounts of salt ${ }^{(26)}$. The nutritional properties of plant-based milk alternatives have also been found to vary, depending on plant source and fortification with micronutrients such as calcium, B12 and iodine in particular ${ }^{(27-29)}$. Mäkinen et al., therefore, highlight the importance for manufacturers to consider nutrient content and quality if these products are to be marketed as substitutes for cow's milk ${ }^{(27)}$.
As the appeal of plant-based meat and dairy substitutes spreads to a wider population, the potential consequences for public health need to be addressed ${ }^{(17)}$. Little is known about the nutritional composition of meat and dairy substitute products on sale in Norway. Moreover, no specific regulations governing the nutrient content of these products are currently in place. The main object of this explorative study is, therefore, to evaluate the macronutrient composition of meat and dairy substitutes available on the Norwegian market, and compare them with their animal-based analogues.

\section{Materials and methods}

\section{Store selection}

Mapping was conducted of plant-based meat and dairy substitute products on sale in three Norwegian online grocery stores between March and April 2020. The three stores (kolonial.no, meny.no and matlevering.coop.no) were selected because they represent retailers holding the majority of the total grocery market share in Norway, NorgesGruppen (44\%), Coop (29\%) and Rema $1000(23 \%)^{(30)}$. Special health food or vegan online stores were excluded because these stores are not commonly used by the general public. In addition, two grocery stores were physically visited. Due to COVID-19 control measures, the stores had to be situated nearby the researcher collecting the data, and the two largest grocery stores in close proximity to the researcher were thus chosen. Tightened restrictions also prevented further stores to be visited. Therefore, the remainder of the data collection, including the supplementary search carried out between 1 October and 16 October, was conducted exclusively on online stores. The two searches were carried out in connection with the spring and autumn 2020 release of new products.

\section{Product selection}

All available plant-based substitute products in the visited online and physical stores, including those temporarily sold out, were registered in a database.

Animal-based samples were selected based on the same usability as their plant-based counterparts. Best comparable usability was defined by product type, product name and description, flavour and texture. Furthermore, two sets of criteria for the inclusion of counterparts were used to form two different groups for comparison purposes. The first group, representing the healthiest animal-based options, only included products carrying the Keyhole label ${ }^{(13)}$. The other group, representing commonly used products, included well-known brands in addition to the three retailer's own brands. 'Most common' was defined as most popular according to 'sort by popularity' in two of three online websites and/or available in all three online stores. In this group, the exclusion criteria were the Keyhole label and additional flavouring that did not match the plant-based comparable option. In categories where the number of suitable counterparts was high, the most common products with the best comparable usability 
were selected. In cases where the number of products was high, a decision on which products to include was made by the project group. If available, an animal-based equivalent from the same producer as the plant-based product was chosen. In some cases, nutritional composition data were unavailable. These products were included in the database but excluded from the statistical analysis.

\section{Data entry}

The final database contained 102 meat substitute products and 173 milk and dairy substitute products (Table 1). A total of ninety-eight meat products, twenty-eight of which carried the Keyhole label and seventy of which were selected as commonly used products, were registered as meat counterparts. Similarly, 105 milk and dairy products, including 15 carrying the Keyhole label and 90 representing commonly used products, were registered. Plant-based meat substitutes and meat counterparts were categorised as burgers, sausages, mince, meatballs, nuggets and schnitzels and cold cuts. Each category comprised a minimum of five products. The remaining products constituted a residual category. Due to heterogeneity in product type and usability, this category was excluded from statistical analysis. Milk and dairy substitutes and counterparts were categorised as creams and crème fraiche, cheese, flavoured drinks and iced coffee, milk, ice creams and yoghurts. In the cheese category, where identical products were available in both blocks and slices, 'slices' were excluded from the statistical analysis. Other products excluded from the dairy categories were yoghurts with granola or muesli. Nutrition composition data were obtained from the producer's website if available. Otherwise, information on nutrient content was retrieved from one of the online stores or the website of a distributor at www.askoservering.no/. The nutrition

Table 1. Number of registered substitute products and meat and dairy products according to product categories

\begin{tabular}{|c|c|c|c|c|}
\hline \multirow[b]{2}{*}{ Category } & \multicolumn{2}{|c|}{ Substitute products } & \multirow[b]{2}{*}{$\begin{array}{l}\text { Keyhole } \\
\text { products }\end{array}$} & \multirow[b]{2}{*}{$\begin{array}{l}\text { Regular } \\
\text { products }\end{array}$} \\
\hline & Database & $\begin{array}{l}\text { Statistical } \\
\text { analysis }\end{array}$ & & \\
\hline & $(n$ 102) & $(n 82)$ & $(n 28)$ & $(n 70)$ \\
\hline Burgers & 21 & 21 & 2 & 18 \\
\hline Sausages & 14 & 14 & 7 & 11 \\
\hline Mince & 13 & 13 & 13 & 13 \\
\hline Meatballs & 10 & 10 & 1 & 10 \\
\hline $\begin{array}{l}\text { Nuggets/ } \\
\text { schnitzel }\end{array}$ & 12 & 12 & 2 & 10 \\
\hline Cold cuts & 12 & 12 & 3 & 8 \\
\hline Others & $\begin{array}{l}20 \\
(n 173)\end{array}$ & $\begin{array}{l}0 \\
(n 162)\end{array}$ & $\begin{array}{l}0 \\
(n 15)\end{array}$ & $\begin{array}{l}0 \\
(n 90)\end{array}$ \\
\hline Cheese & 39 & 36 & 5 & 25 \\
\hline $\begin{array}{l}\text { Creams/ crème } \\
\text { fraîche }\end{array}$ & 9 & 9 & 0 & 4 \\
\hline $\begin{array}{l}\text { Flavoured drinks/ } \\
\text { iced coffees }\end{array}$ & 10 & 10 & 0 & 10 \\
\hline $\begin{array}{l}\text { Milk (unflavoured } \\
\text { drinks) }\end{array}$ & 44 & 41 & 10 & 9 \\
\hline Ice creams & 24 & 24 & 0 & 23 \\
\hline Yoghurts & 47 & 42 & 0 & 19 \\
\hline
\end{tabular}

declaration provided by the food industry was considered reliable ${ }^{(31)}$. Nutrient content of total fat, saturated fat, carbohydrates, sugars, proteins, fibre and salt for all products was reported in grams, milligrams or micrograms per 100 grams. Information collected on energy was reported in kilojoules and kilocalories. For products identified in both the main and supplementary searches, nutritional information from the main search was used. All records of nutritional information were checked against the information on the websites by two researchers in the team. In cases where discrepancies between the recorded values and the information on the websites were detected, values likely due to typing errors were changed, and values likely due to changes in recipes were retained.

\section{Statistics}

Plant-based substitute products for meat (M-Substitutes) were compared with Keyhole-labelled meat (M-Keyhole) and 'Regular' meat (M-Regular). Similarly, plant-based products for dairy (D-Substitutes) were compared with Keyhole-labelled dairy products (D-Keyhole) and 'Regular' dairy products (D-Regular). Data were reported as the median nutrient content of macronutrients and salt measured in grams per 100 grams of product and energy percentage (E\%) in the three groups. The normality of data distribution was tested through the Shapiro-Wilk test and visual examination of QQ-plots, and rejected. Sub-categories with three groups (Substitutes, Keyhole and Regular) were compared using the Kruskal-Wallis test with pairwise comparisons. In the sub-categories that did not include Keyhole-labelled products (creams and crème fraiche, flavoured drinks and iced coffees, ice creams and yoghurts), comparisons were made between D-Substitutes and D-Regular using the Mann-Whitney $U$ test. In all tests, a $P$-value below 0.05 was regarded significant. All analyses were conducted in IBM SPSS statistics 28 (IBM Corp., Armonk, NY, USA).

\section{Results}

The total sample of products included six sub-categories: eighty-two M-Substitutes, twenty-eight M-Keyhole and M-Regular, all from six sub-categories (Table 1). Likewise, from six sub-categories: 162 D-Substitutes, 15 D-Keyhole and 90 D-Regular.

\section{Meat substitute products and meat products}

Overall, M-Substitute products contained more fibre than both M-Keyhole and M-Regular products (both $P<0 \cdot 001$ ) (Table 2) (Table 5 and 6 in supplements). In all but one category (cold cuts), median fibre content per $100 \mathrm{~g}$ ranged from 3.5 to $5.0 \mathrm{~g}$ in M-Substitute products, whereas the median fibre content in both meat groups was $0.0 \mathrm{~g}$ (Table 3). When comparing all products, median saturated fat content in M-Substitutes was 2 times lower than in M-Keyhole $(P<0.001)$ and 5.8 times lower than in M-Regular $(P<0 \cdot 001)$ (Table 2). Similar differences in saturated fat content were observed in all sub-categories between 
Table 2. Differences in nutrient content between all plant-based substitute products for meat and dairy, meat and dairy products with keyhole and meat dairy products without keyhole per 100 grams of product

All meat substitute products and meat, median (IQR)

\begin{tabular}{|c|c|c|c|c|c|c|c|}
\hline \multirow{2}{*}{$\frac{\text { Nutrients per } 100 \mathrm{~g}}{\text { Energy (kcal) }}$} & \multicolumn{2}{|c|}{ Substitutes ( $n$ 82) } & \multicolumn{2}{|c|}{ Keyhole (n 28) } & \multicolumn{2}{|c|}{ Regular ( $n 70)$} & \multirow{2}{*}{$\frac{P \text {-value* }}{<0.001}$} \\
\hline & 201.5 & $(169 \cdot 5-220.5)^{a}$ & $145 \cdot 0$ & $(125 \cdot 0-155 \cdot 8)^{b}$ & 224.5 & $(204 \cdot 8-244 \cdot 3)^{c}$ & \\
\hline Fat $(g)$ & $10 \cdot 2$ & $(8 \cdot 1-15 \cdot 0)^{a}$ & $7 \cdot 2$ & $(5 \cdot 0-9 \cdot 0)^{\mathrm{b}}$ & $16 \cdot 5$ & $(14.0-18 \cdot 1)^{\mathrm{c}}$ & $<0.001$ \\
\hline Saturated fat $(\mathrm{g})$ & $1 \cdot 1$ & $(0.8-1 \cdot 7)^{b}$ & $2 \cdot 3$ & $(2 \cdot 0-3 \cdot 1)^{b}$ & $6 \cdot 4$ & $(5 \cdot 6-7 \cdot 7)^{\mathrm{a}}$ & $<0.001$ \\
\hline Carbohydrates (g) & $8 \cdot 4$ & $(4 \cdot 9-12 \cdot 6)^{a}$ & 0.1 & $(0.0-5.5)^{b}$ & $4 \cdot 0$ & $(0 \cdot 0-7 \cdot 1)^{b}$ & $<0.001$ \\
\hline Sugars $(g)$ & 1.0 & $(0.6-1 \cdot 7)^{a}$ & 0.0 & $(0.0-0.4)^{b}$ & 0.2 & $(0.0-1.0)^{c}$ & $<0.001$ \\
\hline Fibre $(\mathrm{g})$ & $3 \cdot 6$ & $(0.0-5 \cdot 1)^{a}$ & 0.0 & $(0.0-0.0)^{b}$ & 0.0 & $(0.0-0.0)^{\mathrm{b}}$ & $<0.001$ \\
\hline Protein (g) & $13 \cdot 0$ & $(8 \cdot 3-16 \cdot 3)^{a}$ & $18 \cdot 0$ & $(11.5-19.8)^{b}$ & $15 \cdot 0$ & $(11 \cdot 3-17 \cdot 7)^{b}$ & $<0.001$ \\
\hline Salt $(g)$ & 1.5 & $(1 \cdot 1-1 \cdot 8)$ & $1 \cdot 0$ & $(0 \cdot 1-1 \cdot 7)$ & 1.5 & $(1 \cdot 0-1 \cdot 7)$ & 0.081 \\
\hline \multicolumn{8}{|c|}{ All dairy substitute products and dairy with three groups of comparison, median (IQR) } \\
\hline Nutrients per $100 \mathrm{~g}$ & \multicolumn{2}{|c|}{ Substitutes $(n 77)$} & \multicolumn{2}{|c|}{ Keyhole $(n$ 15) } & \multicolumn{2}{|c|}{ Regular ( $n$ 34) } & $P$-value* \\
\hline Energy (kcal) & $62 \cdot 0$ & $(40 \cdot 0-270 \cdot 0)^{b}$ & 38.0 & $(33 \cdot 0-260 \cdot 0)^{b}$ & $277 \cdot 0$ & $(65 \cdot 8-339.8)^{a}$ & $<0.001$ \\
\hline Fat $(\mathrm{g})$ & 3.0 & $(1 \cdot 3-21 \cdot 0)^{a}$ & 0.5 & $(0 \cdot 1-16 \cdot 0)^{\mathrm{b}}$ & $22 \cdot 5$ & $(4 \cdot 0-27 \cdot 0)^{\mathrm{c}}$ & $<0.001$ \\
\hline Saturated fat $(\mathrm{g})$ & 0.6 & $(0.2-18 \cdot 2)^{b}$ & 0.3 & $(0.1-10.0)^{b}$ & $15 \cdot 0$ & $(2 \cdot 6-17 \cdot 0)^{a}$ & 0.001 \\
\hline Carbohydrates (g) & $9 \cdot 4$ & $(4 \cdot 3-20 \cdot 0)^{a}$ & 4.5 & $(0.0-4 \cdot 6)^{\mathrm{b}}$ & $2 \cdot 7$ & $(0.3-4 \cdot 5)^{b}$ & $<0.001$ \\
\hline Sugars $(\mathrm{g})$ & $1 \cdot 8$ & $(0.0-3.9)$ & $4 \cdot 5$ & $(0 \cdot 0-4 \cdot 6)$ & $2 \cdot 0$ & $(0 \cdot 1-4 \cdot 5)$ & 0.480 \\
\hline Fibre $(\mathrm{g})$ & 0.0 & $(0.0-0.6)^{\mathrm{a}}$ & 0.0 & $(0.0-0.0)^{\mathrm{b}}$ & 0.0 & $(0.0-0.0)^{\mathrm{b}}$ & $<0.001$ \\
\hline Protein $(\mathrm{g})$ & 0.5 & $(0 \cdot 1-1 \cdot 3)^{\mathrm{a}}$ & 3.5 & $(3.5-31 \cdot 0)^{b}$ & 11.5 & $(3 \cdot 5-26 \cdot 0)^{\mathrm{b}}$ & $<0.001$ \\
\hline Salt (g) & 0.1 & $(0.1-1 \cdot 9)$ & 0.1 & $(0.1-1 \cdot 1)$ & $1 \cdot 1$ & $(0 \cdot 1-1 \cdot 3)$ & 0.136 \\
\hline \multicolumn{8}{|c|}{ All dairy substitutes products and dairy with two groups of comparison, median (IQR) } \\
\hline Nutrients per $100 \mathrm{~g}$ & \multicolumn{2}{|c|}{ Substitutes $(n 85)$} & & & \multicolumn{2}{|c|}{ Regular ( $n$ 56) } & $P$-value* \\
\hline Energy (kcal) & $103 \cdot 0$ & $(68 \cdot 0-184 \cdot 0)$ & & & $124 \cdot 0$ & $(73 \cdot 3-252 \cdot 0)$ & 0.117 \\
\hline Fat (g) & $7 \cdot 0$ & $(2 \cdot 0-10 \cdot 2)$ & & & 8.3 & $(2 \cdot 9-13 \cdot 3)$ & 0.187 \\
\hline Saturated fat (g) & 1.7 & $(0 \cdot 3-7 \cdot 0)$ & & & $5 \cdot 4$ & $(1 \cdot 8-7 \cdot 8)$ & 0.005 \\
\hline Carbohydrates (g) & $10 \cdot 0$ & $(6 \cdot 8-23 \cdot 5)$ & & & $12 \cdot 0$ & $(5 \cdot 7-24 \cdot 0)$ & 0.535 \\
\hline Sugars (g) & $7 \cdot 5$ & $(3 \cdot 9-18 \cdot 5)$ & & & $11 \cdot 0$ & $(5 \cdot 7-22 \cdot 4)$ & 0.001 \\
\hline Fibre (g) & 0.8 & $(0.0-1 \cdot 0)$ & & & 0.0 & $(0.0-0.0)$ & $<0.001$ \\
\hline Protein (g) & 1.4 & $(1 \cdot 0-3 \cdot 3)$ & & & 3.7 & $(3.5-4 \cdot 4)$ & $<0.001$ \\
\hline Salt (g) & 0.1 & $(0 \cdot 1-0 \cdot 2)$ & & & 0.1 & $(0.1-0.2)$ & 0.107 \\
\hline
\end{tabular}

IQR, Inter Quartile Range.

${ }^{a, b, c}$ Groups with different superscript differ in Kruskal-Wallis pairwise comparison $(P<0.05)$.

${ }^{*}$ Kruskal-Wallis test for differences between three groups of comparison (categories: cheese and milks (unflavoured drinks)); Mann-Whitney $U$ test for differences between two groups of comparison (categories: creams/crème fraiche, flavoured drinks/iced coffees, ice creams, yoghurts).

M-Substitutes and M-Regular (Table 3), but not between M-Substitutes and M-Keyhole. The only difference in salt content was found in mince, where M-Substitutes contained ten times more salt than M-Keyhole $(P=0 \cdot 001)$, and five times more than M-Regular $(P=0.010)$ (Table 3). Overall, protein content was lower in M-Substitutes than in both M-Keyhole $(P<0 \cdot 001)$ and M-Regular $(P=0 \cdot 007)$ (Table 2). However, only the sub-categories burgers and mince had significantly different protein content (Table 3). In burgers, M-Substitutes contained less protein than both M-Keyhole $(P=0 \cdot 007)$ and M-Regular $(P=0.002)$. In mince, M-Substitutes contained less protein than M-Keyhole $(P=0 \cdot 010)$. As expected, the overall carbohydrate content was higher in M-Substitutes than in both meat groups (both $P<0 \cdot 001$ ), but differed only in the sub-categories, burgers and mince (Table 3). M-Substitutes contained more carbohydrates than both M-Keyhole (burgers: $P=0.005$, mince: $P<0.001$ ) and M-Regular (burgers: $P<0 \cdot 001$, mince: $P<0 \cdot 001$ ).

\section{Milk and dairy substitute products and milk and dairy}

Combined D-Substitutes for milk and cheese had seven times lower protein content than D-Keyhole $(P<0 \cdot 001)$ and twentythree times lower than D-Regular $(P<0 \cdot 001)$ (Table 2). Overall, lower protein content in $\mathrm{D}$-substitutes than in D-Regular was also found in creams/crème fraiche, favoured drinks/iced coffees, ice creams and yoghurts $(P<0 \cdot 001)$. Lower protein content in D-Substitutes than D-Keyhole and D-Regular was also found across all sub-categories (Table 4 and Table 7 in supplements). D-Substitutes for milk and cheese had an overall higher carbohydrate content than D-Keyhole and D-Regular (both $P<0.001$ ) (Table 2). However, the overall carbohydrate content in the remaining categories did not differ between D-Substitutes and D-Regular. The saturated fat content in both D-Substitutes and D-Keyhole in combined analysis for milk and cheese was substantially lower than in D-Regular $(P=0.003, P<0.001$, respectively) (Table 2). However, no significant difference was found in the combined analysis of creams/crème fraiche, favoured drinks/iced coffees, ice creams and yoghurts, and there were wide variations between sub-categories (Tables 2 and 4). In cheese, the median saturated fat content in D-Substitutes was 1.9 times higher than in D-Keyhole $(P=$ 0.003), but no difference was found in comparison with D-Regular. The opposite applied to milk, where both D-Substitutes and D-Keyhole had four times lower saturated fat content than D-Regular (both $P<0 \cdot 001$ ). No difference in saturated fat content was observed in yoghurts and ice creams. However, D-Substitutes in flavoured drinks/iced coffees contained less saturated fat than D-Regular $(P<0 \cdot 001)$. Salt content differed only in cheese, where D-Substitutes contained 1.8 times 
Table 3. Differences in nutrient content between plant-based meat substitutes, meat with keyhole and meat without keyhole per $100 \mathrm{~g}$ of product, according to burgers, sausages, mince and meatballs sub-categorisation

Burgers, median (IQR)

\begin{tabular}{|c|c|c|c|c|c|c|c|}
\hline \multirow{2}{*}{$\begin{array}{l}\text { Nutrients per } 100 \mathrm{~g} \\
\text { Energy (kcal) }\end{array}$} & \multicolumn{2}{|c|}{ Substitutes ( $n$ 21) } & \multicolumn{2}{|c|}{ Keyhole $(n 2)^{\dagger}$} & \multicolumn{2}{|c|}{ Regular ( $n$ 18) } & \multirow{2}{*}{$\frac{P \text {-value }}{0.002}$} \\
\hline & $183 \cdot 0$ & $(161 \cdot 5-206 \cdot 0)^{b}$ & $127 \cdot 5^{\mathrm{b}}$ & & $225 \cdot 0$ & $(210 \cdot 0-231 \cdot 0)^{\mathrm{a}}$ & \\
\hline Fat $(\mathrm{g})$ & 9.0 & $(5 \cdot 8-13 \cdot 5)^{\mathrm{b}}$ & $5 \cdot 8^{\mathrm{b}}$ & & $17 \cdot 3$ & $(15 \cdot 0-18 \cdot 0)^{a}$ & $<0.001$ \\
\hline Saturated fat $(\mathrm{g})$ & 0.8 & $(0.6-4 \cdot 2)^{a}$ & $2 \cdot 1$ & & $7 \cdot 8$ & $(6 \cdot 3-8 \cdot 2)^{\mathrm{b}}$ & $<0.001$ \\
\hline Carbohydrates (g) & $9 \cdot 8$ & $(5 \cdot 9-12 \cdot 5)^{\mathrm{a}}$ & $0.1^{\mathrm{b}}$ & & $1 \cdot 3$ & $(0 \cdot 0-3 \cdot 0)^{b}$ & $<0.001$ \\
\hline Sugars (g) & $1 \cdot 3$ & $(0 \cdot 9-2 \cdot 1)^{\mathrm{a}}$ & $0.0^{\mathrm{b}}$ & & 0.0 & $(0 \cdot 0-0 \cdot 1)^{b}$ & $<0.001$ \\
\hline Fibre $(g)^{\ddagger}$ & 3.5 & $(0 \cdot 0-5 \cdot 3)^{a}$ & 0.0 & & 0.0 & $(0.0-0.0)^{\mathrm{b}}$ & $<0.001$ \\
\hline Protein $(g)$ & $12 \cdot 0$ & $(6 \cdot 9-15 \cdot 5)^{\mathrm{a}}$ & $19 \cdot 0^{\mathrm{b}}$ & & $15 \cdot 7$ & $(15 \cdot 0-17 \cdot 7)^{b}$ & 0.001 \\
\hline Salt $(g)$ & $1 \cdot 2$ & $(1.0-1.5)$ & 0.8 & & $1 \cdot 0$ & $(1 \cdot 0-1 \cdot 2)$ & $0 \cdot 114$ \\
\hline \multicolumn{8}{|c|}{ Sausages, median (IQR) } \\
\hline Nutrients per $100 \mathrm{~g}$ & \multicolumn{2}{|c|}{ Substitutes ( $n$ 14) } & \multicolumn{2}{|c|}{ Keyhole $(n 7)$} & \multicolumn{2}{|c|}{ Regular ( $n$ 11) } & $P$-value \\
\hline Energy (kcal) & $198 \cdot 5$ & $(173 \cdot 8-223 \cdot 3)^{a}$ & $148 \cdot 0$ & $(146 \cdot 0-156 \cdot 0)^{b}$ & $241 \cdot 0$ & $(222 \cdot 0-250 \cdot 0)^{c}$ & $<0.001$ \\
\hline Fat $(\mathrm{g})$ & 11.5 & $(10 \cdot 0-16 \cdot 3)^{a}$ & $9 \cdot 0$ & $(9 \cdot 0-10 \cdot 0)^{\mathrm{b}}$ & $18 \cdot 5$ & $(18.0-19 \cdot 9)^{\mathrm{c}}$ & $<0.001$ \\
\hline Saturated fat $(\mathrm{g})$ & $1 \cdot 3$ & $(0.9-4.7)^{\mathrm{b}}$ & $3 \cdot 2$ & $(2 \cdot 9-3 \cdot 2)^{b}$ & $7 \cdot 1$ & $(6 \cdot 9-7 \cdot 2)^{a}$ & $<0.001$ \\
\hline Carbohydrates (g) & $6 \cdot 3$ & $(4 \cdot 4-10 \cdot 3)$ & $5 \cdot 5$ & $(5 \cdot 3-6 \cdot 2)$ & $5 \cdot 6$ & $(5 \cdot 0-6 \cdot 3)$ & 0.781 \\
\hline Sugars $(\mathrm{g})$ & $1 \cdot 1$ & $(0.7-1 \cdot 7)^{\mathrm{a}}$ & 0.5 & $(0.4-0.7)^{b}$ & 0.7 & $(0.4-1.3)$ & 0.044 \\
\hline Fibre $(\mathrm{g})$ & 3.5 & $(0.0-4 \cdot 6)^{\mathrm{a}}$ & 0.0 & $(0.0-0.0)^{b}$ & 0.0 & $(0.0-0.0)^{b}$ & $<0.001$ \\
\hline Protein (g) & $13 \cdot 0$ & $(8 \cdot 3-15 \cdot 4)$ & $11 \cdot 0$ & $(10 \cdot 0-11 \cdot 0)$ & $10 \cdot 0$ & $(9.9-14.5)$ & 0.860 \\
\hline Salt (g) & 1.8 & $(1 \cdot 3-1 \cdot 9)$ & 1.7 & $(1 \cdot 7-1 \cdot 8)$ & $1 \cdot 7$ & $(1 \cdot 6-1 \cdot 9)$ & 0.954 \\
\hline \multicolumn{8}{|l|}{ Mince, median (IQR) } \\
\hline Nutrients per $100 \mathrm{~g}$ & \multicolumn{2}{|c|}{ Substitutes ( $n$ 13) } & \multicolumn{2}{|c|}{ Keyhole ( $n$ 13) } & \multicolumn{2}{|c|}{ Regular ( $n$ 13) } & $P$-value* \\
\hline Energy (kcal) & $195 \cdot 0$ & $(157.5-220 \cdot 0)^{b}$ & $129 \cdot 0$ & $(120.5-146.5)^{a}$ & $202 \cdot 0$ & $(200 \cdot 0-205 \cdot 0)^{b}$ & $<0.001$ \\
\hline Fat $(g)$ & 9.6 & $(4 \cdot 3-13 \cdot 7)^{\mathrm{b}}$ & $5 \cdot 0$ & $(4 \cdot 9-8 \cdot 3)^{b}$ & $14 \cdot 0$ & $(14 \cdot 0-14 \cdot 0)^{\mathrm{a}}$ & $<0.001$ \\
\hline Saturated fat (g) & $1 \cdot 3$ & $(0.5-5.5)^{b}$ & $2 \cdot 3$ & $(2 \cdot 1-2 \cdot 6)^{\mathrm{b}}$ & $6 \cdot 3$ & $(6 \cdot 2-7 \cdot 2)^{\mathrm{a}}$ & 0.001 \\
\hline Carbohydrates (g) & $5 \cdot 3$ & $(3 \cdot 3-9.5)^{\mathrm{a}}$ & $0 \cdot 0$ & $(0 \cdot 0-0 \cdot 0)^{\mathrm{b}}$ & 0.0 & $(0 \cdot 0-0 \cdot 0)^{\mathrm{b}}$ & $<0.001$ \\
\hline Sugars (g) & 0.8 & $(0 \cdot 5-1 \cdot 7)^{\mathrm{a}}$ & $0 \cdot 0$ & $(0 \cdot 0-0 \cdot 0)^{\mathrm{b}}$ & $0 \cdot 0$ & $(0 \cdot 0-0 \cdot 0)^{\mathrm{b}}$ & $<0.001$ \\
\hline Fibre (g) & 4.9 & $(0 \cdot 0-5 \cdot 9)^{\mathrm{a}}$ & 0.0 & $(0 \cdot 0-0 \cdot 0)^{b}$ & 0.0 & $(0 \cdot 0-0 \cdot 0)^{\mathrm{b}}$ & $<0.001$ \\
\hline Protein (g) & $17 \cdot 3$ & $(14 \cdot 3-19 \cdot 8)^{a}$ & $19 \cdot 0$ & $(19 \cdot 0-21 \cdot 5)^{b}$ & $19 \cdot 0$ & $(17 \cdot 5-19 \cdot 4)$ & 0.031 \\
\hline Salt (g) & 1.0 & $(0.6-1 \cdot 7)^{\mathrm{a}}$ & $0 \cdot 1$ & $(0 \cdot 1-1 \cdot 0)^{b}$ & 0.2 & $(0 \cdot 1-1 \cdot 0)^{b}$ & 0.002 \\
\hline \multicolumn{8}{|c|}{ Meatballs, median (IQR) } \\
\hline Nutrients per $100 \mathrm{~g}$ & \multicolumn{2}{|c|}{ Substitutes ( $n$ 10) } & \multicolumn{2}{|c|}{ Keyhole $(n 1)$} & \multicolumn{2}{|c|}{ Regular $(n 10)$} & $P$-value ${ }^{*}$ \\
\hline Energy (kcal) & 184.5 & $(167 \cdot 5-214 \cdot 0)$ & $156 \cdot 0$ & $(156 \cdot 0-156 \cdot 0)$ & $205 \cdot 0$ & $(181 \cdot 8-220 \cdot 5)$ & 0.191 \\
\hline Fat $(\mathrm{g})$ & 9.4 & $(5 \cdot 8-12 \cdot 5)^{\mathrm{a}}$ & 8.7 & $(8 \cdot 7-8 \cdot 7)$ & $14 \cdot 2$ & $(12 \cdot 8-16 \cdot 0)^{\mathrm{b}}$ & 0.008 \\
\hline Saturated fat (g) & $1 \cdot 0$ & $(0.7-1 \cdot 2)^{a}$ & $2 \cdot 0$ & $(2 \cdot 0-2 \cdot 0)$ & $5 \cdot 6$ & $(3 \cdot 7-6 \cdot 2)^{\mathrm{b}}$ & $<0.001$ \\
\hline Carbohydrates (g) & $10 \cdot 0$ & $(6 \cdot 2-14 \cdot 4)$ & 4.9 & $(4 \cdot 9-4 \cdot 9)$ & 4.9 & $(4 \cdot 2-6 \cdot 8)$ & 0.067 \\
\hline Sugars (g) & $1 \cdot 1$ & $(0 \cdot 9-2 \cdot 0)$ & 0.4 & $(0.4-0.4)$ & 1.0 & $(0.2-1 \cdot 4)$ & 0.322 \\
\hline Fibre (g) & 4.5 & $(0 \cdot 0-5 \cdot 3)$ & 0.0 & $(0.0-0.0)$ & 0.0 & $(0.0-0.4)$ & 0.063 \\
\hline Protein (g) & $13 \cdot 7$ & $(8 \cdot 1-18 \cdot 1)$ & $14 \cdot 0$ & $(14 \cdot 0-14 \cdot 0)$ & $13 \cdot 5$ & $(10 \cdot 8-14 \cdot 9)$ & 0.955 \\
\hline Salt (g) & 1.5 & $(1 \cdot 1-1 \cdot 6)$ & 1.7 & $(1 \cdot 7-1 \cdot 7)$ & $1 \cdot 8$ & $(1 \cdot 6-1 \cdot 9)$ & 0.111 \\
\hline
\end{tabular}

IQR, Inter Quartile Range.

${ }^{a, b, c}$ Groups with different superscript differ in Kruskal-Wallis pairwise comparison $(P<0.05)$

${ }^{*}$ Kruskal-Wallis test for differences between groups.

${ }^{\dagger}$ IQR missing due to $n=2$.

‡ Differences between Keyhole and Regular in percentiles outside IQR.

more salt than D-Keyhole $(P=0.012)$ and 1.7 times more salt than D-Regular $(P<0 \cdot 001)$.

\section{Discussion}

To the best of our knowledge, the present study is the first in Norway to compare the available selection of meat and dairy substitute products with animal-based products. Overall results indicated that both meat substitutes and Keyhole-labelled meat have a lower content of saturated fat and higher content of fibre than Regular meat. However, the protein content in the dairy substitutes was considerably lower than in the Keyhole-labelled and Regular dairy products.

\section{Meat substitutes}

In agreement with previous studies, meat substitute products had a higher fibre content than Regular meat products ${ }^{(22,26)}$.
As meat do not contain fibre, and many substitute products are based on plant foods that are rich in fibre ${ }^{(26)}$, these results were as expected. There is a general consensus that increased intake of dietary fibre can have health benefits such as lower risk of hypertension, stroke, obesity and certain gastrointestinal conditions and diseases ${ }^{(32)}$. Since an increased intake of fibre may reduce cholesterol and high blood pressure ${ }^{(32)}$, it is advised to increase the fibre intake in the Norwegian population. The intake of dietary fibre in the Norwegian population is currently lower than the recommended $3 \mathrm{~g}$ per megajoule ${ }^{(15)}$. Although, it is the whole composition of the diet that ultimately determines the total intake of fibre, replacing meat for meat substitutes may contribute to increase overall fibre in the diet. However, there is insufficient knowledge about whether nutrients in processed products offer the same health benefits as the whole foods on which they are based $^{(17)}$. 
Table 4. Differences in nutrient content between plant-based substitute products, dairy with keyhole and dairy without keyhole per 100 grams of product, according to sub-categories cheese, milk (unflavoured drinks) and yoghurts

\begin{tabular}{|c|c|c|c|c|c|c|c|}
\hline \multirow{2}{*}{$\frac{\text { Nutrients per } 100 \mathrm{~g}}{\text { Energy (kcal) }}$} & \multicolumn{2}{|c|}{ Substitutes (n 36) } & \multicolumn{2}{|c|}{ Keyhole ( $n 5)$} & \multicolumn{2}{|c|}{ Regular (n 25) } & \multirow{2}{*}{$\frac{P \text {-value* }}{0.006}$} \\
\hline & $270 \cdot 0$ & $(227 \cdot 3-285 \cdot 0)^{\mathrm{b}}$ & $268 \cdot 0$ & $(237.0-270 \cdot 0)^{\mathrm{b}}$ & $300 \cdot 0$ & $(257 \cdot 0-351 \cdot 0)^{\mathrm{a}}$ & \\
\hline Fat $(\mathrm{g})$ & 21.0 & $(20 \cdot 0-23 \cdot 0)^{\mathrm{a}}$ & $16 \cdot 0$ & $(13 \cdot 0-16 \cdot 0)^{\mathrm{b}}$ & $26 \cdot 0$ & $(21 \cdot 0-27 \cdot 0)^{c}$ & $<0.001$ \\
\hline Saturated fat (g) & $18 \cdot 7$ & $(10 \cdot 3-21 \cdot 0)^{\mathrm{b}}$ & $10 \cdot 0$ & $(8 \cdot 0-10 \cdot 5)^{a}$ & $17 \cdot 0$ & $(14 \cdot 0-17 \cdot 0)^{b}$ & 0.010 \\
\hline Carbohydrates (g) & $20 \cdot 0$ & $(9 \cdot 9-21 \cdot 8)^{a}$ & 0.0 & $(0.0-0.0)^{\mathrm{b}}$ & $1 \cdot 0$ & $(0 \cdot 1-2 \cdot 7)^{\mathrm{b}}$ & $<0.001$ \\
\hline Sugars $(\mathrm{g})$ & 0.0 & $(0.0-0.5)$ & 0.0 & $(0.0-0.0)^{a}$ & 0.3 & $(0 \cdot 0-2 \cdot 7)^{b}$ & 0.015 \\
\hline Fibre $(g)$ & 0.0 & $(0.0-0.0)$ & 0.0 & $(0.0-0.0)$ & 0.0 & $(0.0-0.0)$ & 0.392 \\
\hline Protein $(\mathrm{g})$ & 0.2 & $(0.0-0.7)^{a}$ & $31 \cdot 0$ & $(30 \cdot 0-31.5)^{\mathrm{b}}$ & $24 \cdot 0$ & $(6 \cdot 3-27 \cdot 0)^{\mathrm{b}}$ & $<0.001$ \\
\hline Salt $(g)$ & $2 \cdot 0$ & $(1 \cdot 5-2 \cdot 3)^{a}$ & $1 \cdot 1$ & $(1 \cdot 1-1 \cdot 3)^{\mathrm{b}}$ & $1 \cdot 2$ & $(1.0-1.4)^{\mathrm{b}}$ & $<0.001$ \\
\hline \multicolumn{8}{|c|}{ Milks (unflavoured drinks), median (IQR) } \\
\hline Nutrients per $100 \mathrm{~g}$ & \multicolumn{2}{|c|}{ Substitutes ( $n$ 41) } & \multicolumn{2}{|c|}{ Keyhole $(n 10)$} & \multicolumn{2}{|c|}{ Regular ( $n 9)$} & $P$-value* \\
\hline Energy (kcal) & $42 \cdot 0$ & $(30 \cdot 0-54 \cdot 0)^{b}$ & 36.5 & $(33 \cdot 0-38 \cdot 0)^{\mathrm{b}}$ & 43.0 & $(41 \cdot 0-65 \cdot 0)^{\mathrm{a}}$ & 0.012 \\
\hline Fat $(g)$ & $1 \cdot 3$ & $(1 \cdot 1-1 \cdot 9)^{b}$ & 0.3 & $(0.1-0.6)^{\mathrm{a}}$ & $1 \cdot 2$ & $(1 \cdot 0-4 \cdot 0)^{\mathrm{b}}$ & $<0.001$ \\
\hline Saturated fat $(\mathrm{g})$ & 0.2 & $(0.1-0.3)^{b}$ & 0.2 & $(0.1-0.3)^{b}$ & 0.8 & $(0 \cdot 7-2 \cdot 6)^{\mathrm{a}}$ & $<0.001$ \\
\hline Carbohydrates (g) & $5 \cdot 6$ & $(2.4-7.9)$ & 4.5 & $(4 \cdot 5-4 \cdot 6)$ & 4.5 & $(4 \cdot 5-4 \cdot 8)$ & 0.898 \\
\hline Sugars $(\mathrm{g})$ & $2 \cdot 9$ & $(2 \cdot 0-4 \cdot 8)^{\mathrm{a}}$ & 4.5 & $(4 \cdot 5-4 \cdot 6)^{b}$ & 4.5 & $(4 \cdot 5-4 \cdot 8)$ & 0.027 \\
\hline Fibre $(g)$ & 0.5 & $(0.0-0.7)^{a}$ & 0.0 & $(0.0-0.0)^{b}$ & 0.0 & $(0.0-0.0)^{b}$ & $<0.001$ \\
\hline Protein (g) & 0.7 & $(0 \cdot 4-1 \cdot 7)^{\mathrm{a}}$ & 3.5 & $(3.4-3.5)^{b}$ & 3.4 & $(3 \cdot 3-3.5)^{b}$ & $<0.001$ \\
\hline Salt $(g)$ & 0.1 & $(0.1-0.1)$ & 0.1 & $(0.1-0.1)$ & 0.1 & $(0.1-0.1)$ & 0.911 \\
\hline \multicolumn{8}{|c|}{ Yoghurts, median (IQR) } \\
\hline Nutrients per $100 \mathrm{~g}$ & \multicolumn{2}{|c|}{ Substitutes ( $n$ 42) } & & & \multicolumn{2}{|c|}{ Regular (n 19) } & $P$-value* \\
\hline Energy (kcal) & $80 \cdot 0$ & $(67 \cdot 5-107 \cdot 3)$ & & & $86 \cdot 0$ & $(71 \cdot 0-90.0)$ & 0.379 \\
\hline Fat $(\mathrm{g})$ & 2.5 & $(2 \cdot 0-7 \cdot 7)$ & & & 3.0 & $(3.0-3.4)$ & 0.345 \\
\hline Saturated fat $(\mathrm{g})$ & 0.5 & $(0.3-5 \cdot 7)$ & & & $2 \cdot 0$ & $(1.9-2.3)$ & 0.070 \\
\hline Carbohydrates (g) & 8.9 & $(6 \cdot 5-12 \cdot 0)$ & & & $11 \cdot 0$ & $(5 \cdot 6-12 \cdot 0)$ & 0.731 \\
\hline Sugars $(\mathrm{g})$ & $6 \cdot 8$ & $(2 \cdot 6-8 \cdot 1)$ & & & $10 \cdot 0$ & $(5 \cdot 6-11 \cdot 0)$ & 0.001 \\
\hline Fibre $(\mathrm{g})$ & 1.0 & $(0.6-1.0)$ & & & 0.0 & $(0.0-0.0)$ & $<0.001$ \\
\hline Protein $(\mathrm{g})$ & 1.7 & $(1.1-3 \cdot 7)$ & & & $4 \cdot 1$ & $(3 \cdot 7-5)$ & $<0.001$ \\
\hline Salt $(g)$ & 0.1 & $(0.0-0.2)$ & & & 0.1 & $(0.1-0 \cdot 1)$ & 0.826 \\
\hline
\end{tabular}

IQR, Inter Quartile Range.

${ }_{\mathrm{a}, \mathrm{b}, \mathrm{c}}$ Groups with different superscript differ in Kruskal-Wallis pairwise comparison $(P<0.05)$

${ }^{*}$ Kruskal-Wallis test for differences between three groups of comparison (categories: cheese and milks (unflavoured drinks)); Mann-Whitney $U$ test for differences between two groups of comparison (categories: creams/crème fraiche, flavoured drinks/iced coffees, ice creams, yoghurts).

Although debated, reduction of saturated fat in the diet has been found to reduce risk of cardiometabolic diseases ${ }^{(33,34)}$. The World Health Organization recommends limiting intake of saturated fat for a healthy diet ${ }^{(35)}$, and in Norway, the population goal is to keep saturated fat below $10 \%$ of total energy intake ${ }^{(36,37)}$. As meat is one of the main sources of saturated fat, reducing intake of red and processed meat products is recommended ${ }^{(11)}$. The present study found the overall content of saturated fat in plant-based meat substitutes to be almost six times lower than the overall content in Regular meat, and the findings were consistent across all categories. This may suggest that replacing Regular meat products for plant-based products could contribute to reduction of saturated fat intake in the diet. Furthermore, the requirements for producers to apply the Keyhole label include limitations in saturated fat content. Thus, similar or lower content of saturated fat found in substitutes compared to Keyhole-labelled meat, further indicate that meat substitutes may be a healthier choice in terms of saturated fat. These results were consistent with a similar Australian study ${ }^{(26)}$ and may suggest a potential health benefit from choosing meat substitutes over meat. However, another study comparing nutrient content in meat substitutes with meat products observed equal levels of saturated fat in burgers ${ }^{(22)}$.

\section{Milk and dairy substitutes}

Milk and dairy substitutes in the present study contained considerably lower levels of protein compared with products based on cow's milk and were observed in all sub-categories. Although, similar trends have been found in previous studies assessing both milk $^{(25,28)}$ and cheese substitutes ${ }^{(38)}$, protein content may vary both between- and within-product categories ${ }^{(38-40)}$. Craig and Fresán analysed the nutrient content of plant-based beverages according to the type of beverage, and found high median protein content $(8-9 \mathrm{~g} / 100 \mathrm{~g})$ in beverages based on soy, peas or combinations of legumes and nuts/ grains, and low median protein content in $(0 \cdot 1-1 \cdot 3 \mathrm{~g} / 100 \mathrm{~g})$ beverages based on nuts, almonds or rice ${ }^{(40)}$.

As expected, milk and dairy substitutes seemed overall to have a more beneficial saturated fat content compared with regular milk and dairy products, though there were wide variations between the different sub-categories. Previous studies have found fatty acid profiles to vary according to product's plant source, and in dairy substitutes, milks and cheese based on coconut have been found to have the highest content of saturated fats ${ }^{(12,22,25,28,38)}$. It was beyond the scope of this study to investigate nutrient composition according to natural ingredients. Nevertheless, the content of coconut fat may be a 
possible explanation for the median saturated fat content in cheese substitutes, which was close to twice the amount of Keyhole-labelled cheese, and slightly higher than in Regular cheese. Considering the soaring demand and availability of coconut-based substitute products, especially in the dairy categories, the potential impact on nutrient intake should be addressed.

Although the overall salt content did not differ between plant-based milk and dairy substitute products, cheese substitutes contained almost twice as much salt as Keyhole-labelled cheese. These findings may indicate that consumer should be aware of salt levels in some product categories of plant-based substitute.

\section{Strengths and limitations}

The strength of the present study was that the substitute products were compared with both Regular and Keyhole-labelled meat and dairy options. This allowed for a comparison of plant-based substitutes with both the commonly consumed and the healthiest available products. Using Keyhole-labelled products gave the further advantage of including counterparts already complying standardised and known criteria for healthier products. As health is one of the main reasons for choosing a more plant-based diet, this was a valuable comparison. However, a major limitation of the present study was that only macronutrient content was investigated. Animal-based foods are an important source of a range of essential micronutrients, such as iron and zinc, and the only source of B12 $2^{(41,42)}$. An Australian study found meat substitute products to contain less B12, iron and zinc compared with equivalent meat varieties ${ }^{(26)}$. Cow's milk and dairy products are important sources of iodine and calcium ${ }^{(43,44)}$. Unless fortified, plant-based alternatives either do not contain these nutrients or contain insignificant amounts ${ }^{(12,28)}$. This is, of concern, partly because iodine deficiency has re-emerged as a public health problem in Norway, especially among women of reproductive age ${ }^{(45)}$. Young women are also found to be most likely to shift their diet towards more plant-based eating, and might therefore be more susceptible to plant-based milk and dairy alternatives ${ }^{(16,46)}$. Substitute products may provide a culturally and socially convenient path towards a more plant-based diet ${ }^{(47)}$. However, Salome et al. found that the nutritional impact of substitute products in the diet vary, and depend on both the products that are replaced and the substitutes used as replacement $^{(48)}$.

Another limitation in the present study was that the range of regular meat and dairy products was not included. Furthermore, inclusion was not based on real sales numbers, and the criteria aiming to include the most used products resulted in smaller sample of regular meat and dairy products than plant-based substitutes. Furthermore, in some categories, there were only one or two Keyhole-labelled products, and in others, Keyhole-labelled products were not in sale. In the former case, results from the comparisons between substitutes and Keyhole-labelled products could be questioned due to lack of counterparts. Notably, the criteria for the Keyhole label heavily limit the content of nutrients such as sugar, salt and saturated fat. Thus, some product categories may fail to meet the criteria, due to being unhealthy (e.g. ice cream). Other possible explanation for the lack of available Keyhole-labelled products in some sub-categories could be that producers may not wish to make the necessary changes in their products' recipes to meet the criteria, or they have not applied for approval under the Keyhole labelling scheme even though their products meet the criteria.

\section{Conclusion}

In summary, the study results indicate that meat and dairy substitutes on the Norwegian market vary in nutritional composition. Compared to Keyhole and Regular, substitutes contained lower levels of saturated fat, meat substitutes contained higher levels fibre and milk- and dairy substitutes less protein. However, as the market for plant-based substitutes continues to grow, a comprehensive evaluation of the nutritional composition, including micronutrients and possible health benefits and risks is needed.

\section{Supplementary material}

The supplementary material for this article can be found at https://doi.org/10.1017/jns.2022.6.

\section{Acknowledgements}

E. A., L. E. T., L. E. T.* and S. H. formulated the research question; E. A. and S. H. did the study design; E. A. and L. E. T. collected the data; L. E. T. did formal analysis; L. E. T.*, L. E. T. and S. H. did investigation; L. E. T. wrote the original draft; E. A., L. E. T.*, L. E. T. and S. H. reviewed and edited the manuscript; S.H. did supervision and project administration. All authors have read and agreed to the published version of the manuscript. Due to two researchers having identical initials: ${ }^{*}$ L.E. Torheim.

This research was funded by Oslo Metropolitan University.

The authors declare no conflicts of interest.

\section{References}

1. Aleksandrowicz L, Green R, Joy EJM, et al. (2016) The impacts of dietary change on greenhouse gas emissions, land use, water use, and health: a systematic review. PLoS One 11, e0165797.

2. Willett W, Rockström J, Loken B, et al. (2019) Food in the anthropocene: the EAT-lancet commission on healthy diets from sustainable food systems. The Lancet 393, 447-492.

3. AGA (2017) Livestock Solutions for Climate Change. Rome: FAO.

4. Clune S, Crossin E \& Verghese K (2017) Systematic review of greenhouse gas emissions for different fresh food categories. J Cleaner Prod 140, 766-783.

5. Tilman D \& Clark M (2014) Global diets link environmental sustainability and human health. Nature 515, 518-522.

6. FAO (2018) The Future of Food and Agriculture, Alternative Pathways to 2050. Rome: FAO.

7. FAO (2019) FAO's Work on Climate Change - United Nations Climate Change Conference 2019.

8. GBD 2017 Diet Collaborators (2019) Health effects of dietary risks in 195 countries, 1990-2017: a systematic analysis for the global burden of disease study 2017. The Lancet 393, 1958-1972. 
9. Norwegian Institute of Public Health (2017) Injuries, and Risk Factors Study 2015 (GBD 2015).

10. WCRF, AICR (2018) Diet, Nutrition, Physical Activity and Cancer: A Global Perspective. Continuous Update Project Expert Report 2018. World Cancer Research Fund, American Institute for Cancer Research.

11. Norwegian Directorate of Health (2015) The Norwegian Dietary Guidelines.

12. Röös E, Garnett T, Watz V et al. (2018) The Role of Dairy and Plant Based Dairy Alternatives in Sustainable Diets. SLU Future Food Reports 3.

13. Norwegian Directorate of Health (2019) The Keyhole - for Healthier Food. https://www.helsenorge.no/en/kosthold-ogernaring/keyhole-healthy-food/ (accessed 15 October 2020).

14. Bonsmann SSG, Ciriolo E, van Bavel R, et al. (2020) Front-of-Packe Nutrition Labelling Schemes: A Comprehensive Review. Luxembourg: Publications Office of the European Union.

15. Norwegian Directorate of Health (2021) Trends in the Norwegian Diet 2020.

16. Bugge AB \& Alfnes F (2018) Kjottfrie Spisevaner - hva Tenker Forbrukerne? (Meat-Free Eating Habits- What do Consumers Think?). Oppdragsrapport no. 14. Oslo: Forbruksforskningsinstituttet SIFO, Forbruksforskningsinstituttet SIFO OsloMet - storbyuniversitetet.

17. Santo RE, Kim BF, Goldman SE, et al. (2020) Considering plantbased meat substitutes and cell-based meats: a public health and food systems perspective. Front Sustain Food Syst 4, 1-23.

18. Paul AA, Kumar S, Kumar V, et al. (2020) Milk analog: plant based alternatives to conventional milk, production, potential and health concerns. Crit Rev Food Sci Nutr 60, 3005-3023.

19. Ismail I, Hwang Y-H \& Joo S-T (2020) Meat analog as future food: a review. I Anim Sci Technol 62, 111-120.

20. Van Loo EJ, Hoefkens C \& Verbeke W (2017) Healthy, sustainable and plant-based eating: perceived (mis)match and involvement-based consumer segments as targets for future policy. Food Policy 69, 46-57.

21. Sadler MJ (2004) Meat alternatives - market developments and health benefits. Trends Food Sci Technol 15, 250-260.

22. Bohrer BM (2019) An investigation of the formulation and nutritional composition of modern meat analogue products. Food $S_{c i}$ Hum Wellness 8, 320-329.

23. Choudhury D, Singh S, Seah JSH, et al. (2020) Commercialization of plant-based meat alternatives. Trends Plant Sci 25, 1055-1058.

24. Hu FB, Otis BO \& McCarthy G (2019) Can plant-based meat alternatives be part of a healthy and sustainable diet? JAMA 322, 1547-1548.

25. Chalupa-Krebzdak S, Long CJ \& Bohrer BM (2018) Nutrient density and nutritional value of milk and plant-based milk alternatives. Int Dairy J 87, 84-92.

26. Curtain F \& Grafenauer S (2019) Plant-based meat substitutes in the flexitarian age: an audit of products on supermarket shelves. Nutrients 11, 2603.

27. Mäkinen OE, Wanhalinna V, Zannini E, et al. (2016) Foods for special dietary needs: non-dairy plant-based milk substitutes and fermented dairy-type products. Crit Rev Food Sci Nutr 56, 339-349.

28. Vanga SK \& Raghavan V (2018) How well do plant based alternatives fare nutritionally compared to cow's milk? J Food Sci Technol 55, $10-20$.

29. Silva ARA, Silva MMN \& Ribeiro BD (2020) Health issues and technological aspects of plant-based alternative milk. Food Res Int 131, 108972.

30. Nielsen (2021) Dagligvarefasiten 2021. Dagligvarhandelen.
31. European Commission Nutrition Labelling. Which Nutrition Information Is Mandatory on Food Labels? https://ec.europa.eu/ food/safety/labelling-and-nutrition/food-information-consumerslegislation/nutrition-labelling_en (accessed 25 December 2021).

32. Anderson JW, Baird P, Davis RH, Jr., et al. (2009) Health benefits of dietary fiber. Nutr Rev 67, 188-205.

33. Mozaffarian D, Micha R \& Wallace S (2010) Effects on coronary heart disease of increasing polyunsaturated fat in place of saturated fat: a systematic review and meta-analysis of randomized controlled trials (meta-analysis: PUFA intake and CHD). PLoS Med 7, e1000252.

34. Li Y, Hruby A, Bernstein AM, et al. (2015) Saturated fats compared with unsaturated fats and sources of carbohydrates in relation to risk of coronary heart disease: a prospective cohort study. $J A m$ Coll Cardiol 66, 1538-1548.

35. FAO and WHO (2019) Sustainable Healthy Diets - Guiding Principles. Rome: FAO and WHO.

36. Norwegian Ministry of Health and Care Services (2013) NCD-Strategy 2013-2017 for the Prevention, Diagnosis, Treatment and Rehabilitation of Four Noncommunicable Diseases: Cardiovascular Disease, Diabetes, COPD and Cancer. Oslo: Norwegian Ministry of Health and Care Services.

37. National Nutrition Council (2017) Kostråd om fett - en oppdatering og vurdering av kunnskapsgrunnlaget (Dietary guidelines on fat - an update and assessment of the knowledge base).

38. Fresán U \& Rippin H (2021) Nutritional quality of plant-based cheese available in Spanish supermarkets: how do they compare to dairy cheese? Nutrients 13, 3291.

39. Fructuoso I, Romão B, Han H, et al. (2021) An overview on nutritional aspects of plant-based beverages used as substitutes for cow's milk. Nutrients 13, 2650.

40. Craig WJ \& Fresán U (2021) International analysis of the nutritional content and a review of health benefits of non-dairy plant-based beverages. Nutrients 13, 842

41. Gille D \& Schmid A (2015) Vitamin B12 in meat and dairy products. Nutr Rev 73, 106-115.

42. Lim KHC, Riddell LJ, Nowson CA, et al. (2013) Iron and zinc nutrition in the economically-developed world: a review. Nutrients 5, 3184-3211.

43. Jorde R \& Bonaa KH (2000) Calcium from dairy products, vitamin D intake, and blood pressure: the Tromso study. Am J Clin Nutr 71, 1530-1535.

44. Dahl L, Opsahl JA, Meltzer HM, et al. (2003) Iodine concentration in Norwegian milk and dairy products. Br J Nutr 90, 679-685.

45. Henjum S, Brantsæter AL, Kurniasari A, et al. (2018) Suboptimal iodine status and low iodine knowledge in young Norwegian women. Nutrients 10, 941.

46. Modlinska K, Adamczyk D, Maison D, et al. (2020) Gender differences in attitudes to vegans/vegetarians and their food preferences, and their implications for promoting sustainable dietary patterns - a systematic review. Sustainability 12, 6292.

47. Nath J, Prideaux D (2011) The Civilised Burger: Meat Alternatives as a Conversion Aid and Social Instrument for Australian Vegetarians and Vegans.

48. Salomé M, Huneau JF, Le Baron C, et al. (2021) Substituting meat or dairy products with plant-based substitutes has small and heterogeneous effects on diet quality and nutrient security: a simulation study in French adults (INCA3). J Nutr 151, 2435-2445. 